\title{
La aportación de la provincia de Álava a la contienda hispano- portuguesa en los años finales del reinado de Felipe IV (1663-1665)
}

\author{
Juan A. Sánchez Belén *
}

RESUMEN

El artículo analiza la aportación de la provincia de Álava a la defensa de la

Monarquía Hispánica en los años

finales del reinado de Felipe IV. A través del estudio de dos levas, la de 1663 y la de 1665, asi como de los intentos de la Corona de obtener un nuevo servicio de soldados para la defensa de Guipúzcoa, se desprenden dos hechos importantes: uno, que la provincia de Álava siempre estuvo dispuesta a contribuir con soldados ante las urgencias militares, pero no asi con donativos monetarios; dos, que es la Junta General de la Provincia la que aprueba el servicio y la que procede a repartir el cupo de soldados concedidos al rey entre la ciudad de Vitoria y las hermandades provinciales, en las que recae el encargo de reclutar los soldados asignados, cuyo desplazamiento hasta su lugar de destino era cuidadosamente controlado

\section{ABSTRACT}

This work analizes the contribution of province of Alava to defense the Hispanic Monarchy in late years of Felipe IV reign. By studing two recruits of soldiers, the ones of 1663 and 1665 , as the attempts of the crown to obtain a new service of soldiers for defending Guipuzcoa, we can infer two important facts. First, province of Álava was always willing to give soldiers to face military emergencies, but never donations. Second, the "Junta General de la Provincia" is the one that approves the service and stablishes a certain number of soldiers given to King between city of Vitoria and the "hermandades provinciales", what are in the charge of recruiting soldiers asigned. The authorities of the Province controled the process of taking the soldiers to province's border. From here, were

- UNED. 
por las autoridades de la Provincia

dentro de su demarcación y por las autoridades militares que los recibian a fin de evitar desmanes $y$ abusos en los lugares por donde transitaban. militar authorities who had to transport them to their final destination, in order to avoid them to commit any kind of excces all along the way.

La firma de la Paz de los Pirineos en 1659 poniendo fin a la contienda hispano-francesa que se había desencadenado en 1635, durante la Guerra de los Treinta Años, será la ocasión, aguardada con impaciencia desde hacia bastantes años, para que Felipe IV y sus consejeros emprendan un último intento - y a la desesperada- por recuperar la soberania perdida de Portugal a raíz de su desafección en 1640, aunque ya se alzaban voces en la Corte partidarias de iniciar negociaciones con Lisboa al objeto de alcanzar un acuerdo de paz, como así plantearon en 1662, sin demasiada fortuna, el conde de Castrillo y el duque de Medina

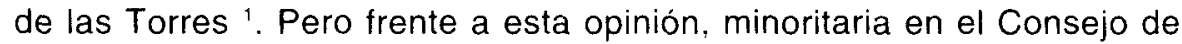
Estado, se impuso la contraria, defendida en el Consejo de Portugal, la de recuperar el reino rebelde al precio que fuera, lo que justifica que entre 1662 y 1665 el monarca exija nuevos sacrificios que afectarán a todos los reinos y señorios de la Monarquía Hispánica, incluidas las Provincias Exentas.

En efecto, a la reforma monetaria decretada en 1661, consistente en acuñar piezas de plata ligada con cobre (moneda de molino) para lo que se destinó, por concesión de los procuradores en Cortes, un millón de escudos de plata a recaudar de la venta de 200.000 ducados de renta del tercer uno por ciento ${ }^{2}$, hay que sumar el donativo aprobado por el reino en 1662 de medio millón de escudos de a diez reales para la campaña de Portugal, el otorgado con el mismo propósito en 1663 por valor de 200.000 escudos de a diez reales y la creación, por último, de un recargo adicional

Valladares, R., Felipe IV y la Restauración de Portugal, Málaga, 1994, págs. 179; StRaDLING. A., "A Spanish Statesman of Appeasement: Medina de las Torres and Spanish Policy, 16391670". Historical Journal, 19, 1976, págs. 1-31.

Esta medida ya habia sido planteada por Felipe IV en 1657, según se recoge en las Actas de las Cortes celebradas en dicho año (Citado por Garcia GuERRA, E.M: “La moneda de vellón: un instrumento al servicio de la fiscalidad del Estado moderno castellano. Un foro de oposición: las Cortes". Cuadernos de Historia Moderna, 21, 1998, págs. 97). Para más datos sobre el tema monetario en el reinado de Felipe IV, ver HAMILTON, E.J., “Inflación monetaria en Castilla (15981660)", El florecimiento del capitalismo. Ensayos de Historia Económica, Madrid, 1984, págs. 59101 y Guerra y precios en España, 1651-1800, Madrid, 1988. 
sobre las compras y ventas: el cuarto uno por ciento ${ }^{3}$. Si estas aportaciones resultaban de por sí dolorosas para una sociedad que había tenido que sufragar los costes de una guerra prolongada por espacio de treinta y ocho años, no lo serían menos las reclutas de soldados que sistemáticamente fueron solicitadas para los ejércitos de los Paises Bajos, Cataluña, Milán y Extremadura ${ }^{4}$. lo que provocará en ocasiones desórdenes y motines contra las levas, como el protagonizado en la Coruña en 1662, y que difiere de la actitud adoptada por los estudiantes de la Universidad de Santiago que se incorporan a filas en 1663 y en 1665, si bien en este caso el ataque a la plaza de Monterrey fue sin duda el acicate que movilizó a una juventud hasta entonces despreocupada de los avatares béli$\cos { }^{5}$. A estos factores hay que añadir los devastadores efectos de los acuartelamientos y tránsitos de soldados por la Corona de Castilla desde 1640, particularmente en la zona fronteriza con Portugal, desde Galicia hasta Huelva ${ }^{6}$, razón por la cual a comienzos de la década de 1660 la Co-

RipA, J. de, Práctica de la administración y cobranza de las rentas reales..., Madrid, 1676, fol. 2; Dominguez Ortiz, A., Política y Hacienda de Felipe IV, Madrid, 1960, pág. 237. Sobre la actitud de las Cortes de Castilla a la concesión de nuevos servicios, además de las referencias contenidas en Strandling, R.A., Felipe IV y el gobierno de España, 1621-1665, Madrid, 1989, págs. 431-432 y en Ruiz Maftin, F., Las finanzas de la Monarquia Hispanica en tiempos de Felipe IV (1621-1665), Madrid, 1990, págs. 77-79, hay que consultar el trabajo de LORENZANA DE LA PUENTE, F., «Política y hacienda en 1660-1664. Las últimas Cortes de Castilla», en J.l. FORTEA PEREZ y C.M. Cremades Grinan (Eds): Política y Hacienda en el Antiguo Régimen. Murcia, 1996, págs. 343-358.

4 Al respecto ver, entre otros, los estudios de ASENJO SEDANO, C., "Una leva para la guerra de Cataluña (La de Guadix, del año 1642". Actas / Congreso de Historia de Andalucia. Andalucía Moderna (siglos xvi y xvil), Córdoba, 1978, I. págs. 61-68; Castilla Soto, J. y A.M. Cubas Regueira, "La aportación de Galicia a la Guerra de Secesion de Portugal (1640-1668)", Espacio, Tiempo y Forma, serie IV , 9, 1996, págs. 231-242; CORTES CORTÉS, F., «La contribución extremeña en las luchas con Portugal (1640-1665). La villa de Los Santos", Homenaje a Dominguez Ortiz, Madrid, 1981; FLORISTAN IMICOZ, A., "Repercusiones de la Rebelión y Guerra de Cataluña en Navarra. Las Cortes de Pamplona de 1642", Actes. Primer Congrés d'Historia Moderna de Catalunya, Barcelona, 1984, II. págs 181-187; JAOUES, J.A. y H. SANCHO DE SOPRANIS, "Alistamiento de nobles y auxilio económico a la Corona en el Puerto de Santa Maria (Cádiz). Año de 1641", Hidalguia, IV, 14, 1956, págs. 81-86; MARCHENA FERNANDEZ, J., "Las levas de soldados a Indias en la Andalucía Siglo XVII", Andalucia y America en el siglo Xvil, Sevilla, 1985. vol. II, págs. 93-117.

Castilla Soto, J. y A.M. Cubas Regueira, "La aportación de Galicia...", pág. 239. Ver tambièn Gonzalez Lopez, E., El Águila caída, Vigo, 1973, pág. 1968 y SaAvedRA, P.

- Sobre las repercusiones de la guerra en la frontera con Portugal, visibles en la evolución demográfica de ciertas localidades, como Mérida y Zafra, por ejemplo (Rodriguez Grajera, A., La población de Mérida en el siglo XVII. Badajoz, 1985. Contés ConTÉs, F., La población de Zafra en los siglos XVI y XVII, Badajoz, 1983, y, en conjunto para Extremadura LLOPIS ANGELAN, E. y otros: «EI movimiento de la población extremeña durante el Antiguo Régimen", Revista de Historia Económica, VIII, 2, 1990, págs. 419-426), se pueden consultar los trabajos de CORTES CORTÉS, F., "Guerra en Extremadura: 1640-1668 (Ejército, financiación y consecuencias)", Revista de Estudios Extremeños, XXXVII, 1, 1982, págs. 37-122 y, sobre todo, Alojamientos de soldados en la Extremadura del siglo xvil. Mérida, 1996; Núñez Roldan, F., "De la crisis de 1640 a la Guerra de Sucesión en la frontera luso-onubense. Las razzias portuguesas y sus repercusiones socioeconó- 
rona adoptará diversas medidas para erradicar los desafueros y evitar que el gasto de los alojamientos recayera sobre los súbditos, liberándolos además de parte de los tributos ${ }^{7}$.

Pero la ofensiva de Felipe IV contra Portugal en 1662, por más que Castilla siguiera soportando el grueso de su financiación, incidirá también en el resto de los territorios hispánicos de la Monarquía. Porque ahora el monarca, aparte de conseguir que Cataluña contribuya con un donativo de 725.196 libras, aunque ciertamente incobrable ya que en realidad se trataba de un traspaso de la deuda que el monarca francés había contraído con la ciudad de Barcelona durante los años 1640-1652 ${ }^{8}$, obtendrá de Zaragoza doscientos hombres para la campaña de 1664 y otros cien más para la de 1665 , al margen de la concesión por el reino de Aragón en 1664, después de cierta resistencia, de una cuarta parte del tercio de cuatrocientos hombres que había sido solicitado para el ejército de Portugal, mientras que Valencia se compromete a subragar durante siete meses un tercio de cuatrocientos soldados por un importe de 25.000 libras, cantidad a la que se sumarán otras 6.000 libras en 1665 para la recluta de un número igual de soldados pero únicamente por dos meses ${ }^{9}$. Navarra, por su parte, aprobará en las Cortes de 1662 , tras varias discusiones, como evidencia el virrey en su correspondencia con Madrid, un servicio de quinientos cuarenta hombres durante cuatro meses, prorrogables a seis si los dos últimos corrian a cargo de la Corona, lo que supondría un coste para las arcas de la Diputación de 4.488.000 maravedies en salarios y manutención, además de otros

micas", Actas // Coloquios de Historia de Andalucia. Andalucia Moderna, Córdoba, 1980, t. II, págs. 117-130; PEREZ EMBtD, F., La frontera entre los reinos de Sevilla y Portugal, Sevilla, 1975; y RODRIGUEz SANCHEZ, A., "Guerra, miseria y corrupción en Extremadura», Estudios dedicados a Carlos Callejo Serrano, Cáceres, 1979, págs. 605-625.

En 1661 Felipe IV decide exonerar de impuestos a todos los pueblos fronterizos con Portugal en un radio de cinco leguas, aunque la medida es revocada en 1663 pese a las protestas de don Juan José de Ausina, tal vez por haberse minorado las disponibilidades financieras de la Corona, lo que no impedirá que se concedan rebajas de carácter temporal a determinados lugares (ARChivo General de Simancas (A.G.S), Consejo y Juntas de Hacienda (C.J.H), legs. 1226 y 1234 , y Contadurias Generales (Con . Gles), leg 748). Respecto a las medidas para evitar los abusos de los alojamientos, BiBlioteca Nacional DE Madrid (B.N.M), Mss 2389, ful. 13, 17 y 18.

- Sanchez Marcos, F.,Cataluña y el gobierno central tras la Guerra de los Segadores (16521679), Barcelona, 1983, pág. 155. De hecho, poco después Felipe IV condonará a Luis XIV una porción de esa deuda (Agradezco a Isabel Yetano la referencia de este dato).

Garcia Martinez, S., Valencia bajo Carlos II, Villena, 1991, pág. 286, nota 12, Armillas VICENTE, J.A., "Acción militar del Estado aragonés contra Portugal (1475-1477 y 1664-1665)", Revista Estudio, Zaragoza, 1979, págs. 209-229 y SANz CAMANES, P., "Municipio, fiscalidad real y empresa militar. Zaragoza y su contribución a la Corona durante el gobierno de los Austrias", en Fernandez Albadalejo, P. (Ed), Monarquia, Imperio y Pueblos en la España Moderna, Alicante, 1997, pág. 502. 
816.000 maravedies para alimentar a los soldados en su desplazamiento hasta reunirse con el ejército real ${ }^{10}$.

La provincia de Álava, como los restantes territorios forales vascos, tampoco permanecerá al margen de las nuevas campañas militares, a pesar de que mantuvo un sistema fiscal privilegiado, pues en la práctica se vió inmersa en la dinámica general de contribuciones a la Corona bajo la fórmula de donativos voluntarios y de levas para los ejércitos reales ". Aun cuando se conoce ya bastante bien la evolución de algunos impuestos en Álava - la alcabala, principalmente- y el aumento de la carga impositiva, que en ningún caso superó la media de una fanega de trigo por vecino, no obstante haberse multiplicado por tres los repartimientos, que ascienden a casi dos millones de maravedies entre 1690 y 1699 , igualando, si no superando, los valores de las contribuciones ordinarias ${ }^{12}$, todavía queda mucho por estudiar sobre esa participación, lo que no sucede con Guipúzcoa ${ }^{13}$. Los datos que hemos obtenido de las levas de los años 1663 y 1665 vienen a confirmar el incremento de la fiscalidad extraordinaria en Álava, porque en el primer caso su aportación se calcula en 1.360 .000 maravedies, a razón de 13.600 maravedies por soldado reclutado, y en el segundo a 1.496.000 maravedies, lo que supone un desembolso por recluta de 14.960 maravedíes, cantidades que se reparten por mitad entre el vestuario y el armamento -en 1663 sólo se entregaron espadas a los soldados-, por un lado, y los salarios, mantenimiento y gastos de la conducción de la tropa hasta los límites provinciales por otro, pues desde el momento en el que las autoridades militares se hacen cargo de las compañías unos y otros corren a cargo de la Real Hacienda ${ }^{14}$.

La disposición de Álava a la recluta de soldados contrasta, empero, con su negativa a contribuir con donativos voluntarios. Es cierto que en un pri-

10 Archivo General de Navarra (A.G.N), Actas de Cortes, 3, fols. 304-312, 346, 358 y 384 , y Reino. Guerra, leg. 4, carpeta 37-43. Sobre la correspondencia del virrey de Navarra, VALLADARES, R., Felipe IV y la restauración..., pág. 61

11 Al menos se sabe que en 1665 Vizcaya y Guipúzcoa contribuyeron con servicios de hombres para la Armada pues asi lo declara la Junta General de Álava en la sesión de 3 de julio de 1665 (Archivo Provincial de Álava (A.P.A), Actas, M 16, ful. 124).

i2 BitbaO, L.M., «Relaciones fiscales entre la provincia de Álava y la Corona. La alcabala en los siglos XVI y XVII", en La formación de Álava. Congreso de Estudios Históricos. Comunicaciones, Vitoria, 1985, vol. I. págs. 73-91. Del mismo autor, "Haciendas forales y hacienda de la Monarquia. El caso vasco, siglos XIV-XV!Il». Historia de la Hacienda en España (Siglos XVi-xx):Homenaje a Felipe Ruiz Martín. Madrid, 1991, págs. 43-58.

13 Al respecto se debe consultar el excelente estudio de Mugartegul, I., "La exención fiscal de los territorios forales vascos: el caso guipuzcoano en los siglos XVII y XVIII", Haciendas Forales y Hacienda Real. Homenaje a D. Miguel Artala y D. Felipe Ruiz Martin, Bilbao, 1990, págs. 175-193.

1.4 Archivo Provincial de Alava (A P.A), Actas, M 16, ful. $27 \mathrm{~V}$. 
mer momento la petición realizada por Felipe IV, en 20 de marzo de 1663, de una leva de cien hombres para la Armada del general Miguel de Oquendo con destino a la campaña que por entonces se estaba preparando contra Portugal ${ }^{15}$, no fue bien recibida, ya que en la sesión del 13 de abril de ese año la Junta Particular de la Provincia resuelve por unanimidad que se escriba al monarca solicitando quedar eximida de ese servicio exponiendo la pobreza de sus habitantes y los continuos servicios prestados, en particular el embargo de setecientas acémilas para transportar armas al ejército de Extremadura ${ }^{16}$. La Corona, desde luego, rechazará de plano semejante resolución, y así lo expone en carta de 20 de abril, insistiendo en ser asistida con dicho servicio, requisitoria que el Diputado General logra imponer a la Junta General reunida el 4 de mayo de 1663 , donde finalmente es aprobada dos días después ${ }^{17}$. A cambio, por supuesto, la Provincia tratará de obtener ciertas compensaciones: así el 6 de mayo de 1663 resuelve incrementar los derechos sobre el vino procedente de La Rioja y prohibir el transporte de lanas castellanas por su territorio en carros y a lomos de acémilas que no pertenezcan a los trajineros locales por el perjuicio que esto causaba a sus moradores ${ }^{18}$; por lo mismo, que entable contactos con Guipúzcoa y Vizcaya tendentes a evitar los embargos de mulas y demás animales de tiro para el transporte de armas al frente portugués ${ }^{19}$. Con todo, esta actitud de cooperación con la Monarquía se enfría en 1664 ante la solicitud por el rey de un donativo voluntario, pues la Junta General se va a oponer a su concesión de forma reiterada, no admitiendo al corregidor de Guipúzcoa a quien la Corona había encargado ejecutar su cobranza ${ }^{20}$. Pese a esta pugna, en 1665 la Provincia vuelve a levantar una compañía de cien soldados, según nueva demanda del rey, aunque ahora se acuerda otorgar el servicio con el requisito de quedar eximida del mencionado donativo ${ }^{21}$. Presionada por los acontecimientos, la Corona parece conformarse con esa decisión, al menos temporalmente, tal como se desprende de la carta que el monarca remite por mano de su secretario, Juan Bautista de Arespacochaga, agradeciendo el ofrecimiento que ha hecho de

Sobre los proyectos navales de estos años, Valladares, R., Felipe IV y la restauración, págs. 151-152.

A.P.A, Actas, M 16, fols. 4v-5. La petición del monarca en los fols. $4-4 \mathrm{v}$.

A.P.A, Actas, M 16, fols. $6 \mathrm{v}$ y $7 \mathrm{v}$.

A.P.A. Actas, M 16, fols. $8 \mathrm{v}$ y $9 \mathrm{v}$.

La propuesta que se realiza consiste en que Guipúzcoa y Vizcaya transporten las armas para el ejército a Vitoria, donde los trajineros de la ciudad las conducirán a moderados precios, a Burgos, y, que desde esta localidad se conduzcan a la frontera con Portugal (A.P.A. Actas. M 16, fols. 7 y 8 ).

20 Sobre el donativo de 1664 y sus avatares, A P.A, Actas, M 16, fols. 86 a 111.

21 A.P.A, Actas. M 16, fol. 110. 
cien hombres para la tripulación de los dos galeones que Pedro de Agüero, marqués de Valdecarzana, estaba construyendo en los astilleros de Colindres $^{22}$, ya que no ignora, como así lo expone,

\begin{abstract}
"las dificultades que ocasiona la falta de medios con que os halláis y la estrecheza de vuestros naturales [...] y hago toda la estimación que merece el singular amor y fidelidad que manifestáis en todas las ocasiones de mi servicio como lo experimentareis en las que se ofrecieren de vuestra mayor conveniencia" ${ }^{23}$.
\end{abstract}

La promesa implícita del monarca a satisfacer las demandas de las Provincia en orden a sus necesidades allana cualquier obstáculo a la realización de esta nueva leva, cuyos preparativos se posponen hasta tener noticias del veedor Luis de Necolalde, superintendente de fábricas y plantíos en la provincia de Guipúzcoa, quien deberá avisar al Diputado General de Álava sobre el momento más adecuado para la recluta a fin de excusar gastos innecesarios y fugas. El 23 de junio de 1665 el veedor, en respuesta a una carta anterior de la Provincia fechada tres días antes, informa que todo está preparado para que los galeones salgan a la mar salvo en lo que respecta al bastimento que corre por factoría, aunque "según la prisa con que se obra en ello parece que para los fines del que viene, ocho días más o menos, estará todo pronto, y conforme la disposición y estado que esto fuere tomando, adelantaré cuando sea posible el aviso de manera que haya lugar para prevenir y entregar la gente". Cinco dias más tarde, el 27 de junio de 1665, Luis de Necolalde escribe avisando de que el día 22 de julio acudirá a "la raya" un comisario para recibir a la gente de guerra. A la vista de estas cartas, el 3 de julio de 1665 la Provincia se reúne en Junta extraordinaria para tratar este asunto procediendo entonces a expedir las órdenes oportunas a las hermandades con la finalidad de que acudan a Vitoria con la gente para alistarla. Contra esta resolución se alza el Procurador General de Vitoria en voto particular, proponiendo que la entrega de la gente de guerra se dilate hasta que la Corona asegure a la Provincia de que no demandará el donativo que había solicitado, ya que la concesión del servicio de los cien soldados se hizo con la condición de que el monarca se abstuviera de pedir el donativo ${ }^{24}$. Para los señores de la Junta es evidente, sin embargo, que no hay motivo

\footnotetext{
22 Para los problemas de este asentista, Valladares, R., Felipe IV y la restauración..., págs. 145-146 y 147 nota 165. Sobre el tonelaje de la marina de guerra española en la segunda mitad del siglo XVII, ver ALCALA ZAMORA y QUEIPO DE LLANO, J., "Evolución del tonelaje de la flota de vela española durante los siglos modernos», Estudios, Zaragoza, 1975, págs. 177-224.

A.P.A, Actas, M 16, fol. 115.

A.P.A, Actas, M 16, fols. $119 \mathrm{v}-120$.
} 
alguno para demorar la entrega de los soldados, pues todo apunta a que el rey aceptó el servicio con la condición referida, pues el corregidor de Guipúzcoa, a quien se había nombrado como comisario para la recaudación del donativo, se había retirado de Vitoria sin proceder a su cobranza, "cuya demostración manifestó con evidencia a todos [...] que lo hizo con orden de Su Majestad, pues infalible que sin ella no hubiera cesado en dicha comisión un ministro tan celoso", aparte de que, según los avisos recibidos de Jerónimo Ruiz Samaniego, comisario de la Provincia en $\mathrm{Ma}$ drid, ni el rey ni la Junta del Donativo se han pronunciado contra las quejas del citado corregidor por las dificultades encontradas en Vitoria sobre el cobro del donativo, de donde se infiere, a su juicio, que han sido aceptadas las condiciones del servicio. No obstante, el motivo fundamental por el cual los diputados prefieren abstenerse de exigir de manera «intempestiva" un documento que contemple lo acordado por la Junta General reside en los riesgos que pueden derivarse de semejante actitud:

"porque, aunque esta Provincia está exenta y privilegiada, querer pactar con el principe con repetidas instancias, después de picar en temeridad y ser muy desagradable a los reales ojos, hay muchos ejemplares en las historias de 10 mal que les ha estado a los que lo han practicado asi, y seria desconsuelo sin alivio experimentar demostraciones de poco cariño de un rey tan grande y benigno, y a quien tanto amor debe esta Provincia, por solicitar lo que se debe excusar con tanta razón por todo lo que va referido" 25.

La táctica empleada en 1665 por los diputados de Álava es, sin duda, inteligente, aun cuando se ve condicionada $-\mathrm{y}$ el texto citado lo pone de manifiesto - por el recuerdo de lo sucedido a los catalanes en 1640, pero también, y en no menor medida, por el conflicto que mantenía con Bilbao en esas fechas ante su pretensión de abrir el puerto de Orduña que desplazaria a Vitoria y San Sebastián del tráfico comercial con Castilla ${ }^{26}$. Frente a un mal mayor la Provincia opta entonces por elegir el menos perjudicial, el de las levas, medio al que de nuevo acudirá la Corona en el mes de septiembre de ese mismo año para fortalecer la plaza de Fuenterrabía ${ }^{27}$ en previsión de que Luis XIV emprendiera una acción militar por sorpresa contra los Países Bajos, como así lo había comunicado a Madrid el marqués de la Fuente, quien recibe esta insinuación de la reina Ana de Austria en el

as A.P.A, Actas, M 16, fols. 120-122.

25 A.P.A, Decretos, leg 16. Decreto de la Junta General de la provincia, 25 de noviembre de 1664; Fernandez Albaladejo, P., La crisis del Antiguo Régimen en Guipúzcoa, 1766-1833. Cambio económico e histórico, Madrid, 1975, págs, 81-82

A.P.A,Actas, M 16, fols. 148-150v. 
mes de agosto de 1665 28; Sin embargo el fallecimiento de Felipe IV, los actos funerarios y el alzamiento del pendón real por Carlos II, en los que se invierten sumas importantes de dinero ${ }^{29}$, postergarán su ejecución hasta que las circunstancias políticas lo aconsejen. Este es, al menos, el sentir de los procuradores de la Provincia, pues el 20 de noviembre de 1665, en respuesta a la petición de gente solicitada por la reina gobernadora, manifiestan que están dispuestos a servir a la Corona "con la fidelidad y lealtad con que siempre ha acostumbrado" pero sólo cuando el peligro sea inminente y no antes, ya que "no hay noticias, aunque se pueden temer, de la invasión que el francés puede hacer", aviniéndose todo lo más a escribir a las hermandades advirtiéndolas de que estén preparadas para cualquier contingencia, y ello por las reiteradas instancias del Diputado General dirigidas a que fuera aprobado el servicio que la Corona habia solicitado en sendas cartas de 22 de septiembre y 30 de octubre de 1665; decisión que fue comunicada a doña Mariana de Austria en los términos siguientes:

"Conferida la materia [...], en mi Junta General, y con la fineza ejemplar de mi fidelidad, he resuelto que, para cuando llegue el lance, servíré a $\mathrm{V}$. Majestad con la gente que pueda para la campaña, a proporción de la urgencia $y$ de mis fuerzas" 30 .

\section{II}

¿Cómo se llevaron a cabo las levas en Álava? El sistema adoptado por la Junta General consistía en repartir la cuota establecida con la Corona entre Vitoria, la Junta de Hidalgos de Elorriaga, los hombres buenos de la jurisdicción de Vitoria y las hermandades de la Provincia, encargando la ejecución del repartimiento al Diputado General que lo haría ante notario para evitar abusos y demandas de los agraviados en el supuesto de que fuera desigual o desproporcionado a la riqueza de los lugares y sus moradores. En el Cuadro I se indican los hombres que corresponden a cada una de ellas así como los soldados finalmente aportados, si bien en la leva de 1665, dado el litigio que Llodio mantiene con la Junta General ${ }^{31}$, se resuelve que

28 Archivo General de Simancas (A.G.S), Estado Francia, leg K.1390. La petición de la Corona está fechada el 22 de septiembre de 1665 y es reiterada en 30 de octubre de ese mismo año (A.P.A, Actas, M 16, fols. 148-150v).

29 Sobre los festejos de proclamación de Carlos 11 , SANCHEZ BELEN, J.A., "Proclamación del monarca en la provincia de Álava durante el siglo xvii», Espacio, Tiempo y Forma, serie IV, 10 , Madrid, 1997, págs. 173-200.

30 A.P.A, Actas, M 16, fols. $161 \mathrm{v}-162 \mathrm{v}$.

31 El conflicto con Llodio, que pretende emanciparse de la jurisdicción de Álava, en A.P.A, Actas, $M 16$, fols. $140 \mathrm{v}-143 \mathrm{v}, 145-147,157 \mathrm{v}-158$ y 171. 
Cuadro 1. Repartimiento de los soldados de las levas de 1663 y 1665

\begin{tabular}{|c|c|c|c|c|}
\hline \multirow[t]{2}{*}{ Hermandades } & \multicolumn{2}{|c|}{ Soldados repartidos } & \multicolumn{2}{|c|}{ Soldados reclutados } \\
\hline & 1663 & 1665 & 1663 & 1665 \\
\hline Ciudad de Vitoria & $61 / 4$ & $61 / 4$ & 7 & 6 \\
\hline Hijosdalgos de Elorriaga & $41 / 4$ & $411_{4}^{4}$ & 7 & 4 \\
\hline Hombres buenos de la jurisdicción de Vitoria & $3 \%$ & $311_{4}^{4}$ & 3 & 4 \\
\hline Salvatierra & $31 / 4$ & $31 / 4$ & 3 & 3 \\
\hline Ayala & $11^{4}$ & $11^{4}$ & 11 & 11 \\
\hline La Guardia & 7 & 7 & 7 & 7 \\
\hline Iruraiz & $33 / 4$ & $33 / 4$ & 4 & 4 \\
\hline Gamboa & $1 \%$ & $11 / 2$ & 1 & 2 \\
\hline Arciniega & $3 / 4$ & $3 / 4$ & 1 & 1 \\
\hline Llodio & 2 & 2 & 2 & 2 \\
\hline Urcabuztaiz & $13 / 4$ & $13 / 4$ & 2 & 2 \\
\hline Guevara & $1 / 2$ & $1 / 2$ & 1 & - \\
\hline Arrastaria & $1^{2}$ & $1^{2}$ & 1 & 1 \\
\hline Arrazua & 1 & 1 & 1 & 1 \\
\hline Ubarrundia & $11 / 4$ & $1 \%$ & 1 & 1 \\
\hline Zuaya & $23 / 4$ & $23 / 4$ & 3 & 2 \\
\hline San Millán & $21 / 4$ & $21 / 4$ & 2 & 2 \\
\hline Aramayona & 1 & 1 & 1 & 1 \\
\hline Arraya y La Minoria & $3 \%$ & $31 / 4$ & 3 & 3 \\
\hline Barrundia & $13 / 4$ & $13 / 4$ & 2 & 2 \\
\hline Bernedo & 1 & 1 & 1 & 1 \\
\hline La Ribera & $51 / 2$ & $51 / 2$ & 6 & 5 \\
\hline Badajoz & $31 / 2$ & $31 / 2$ & 3 & 2 \\
\hline Axparna & $13 / 4$ & $13 / 4$ & 2 & 2 \\
\hline Cigoitia & $31 / 2$ & $31 / 2$ & 3 & 4 \\
\hline Morillas & $3 / 4$ & $3 / 4$ & 1 & - \\
\hline Brantevilla & $11 \frac{4}{4}$ & $11_{4}^{4}$ & 1 & 1 \\
\hline Tierras del conde de Salinas & $31 / 4$ & $31 / 4$ & 3 & 4 \\
\hline Lacozmonte & 1 & 1 & 1 & 1 \\
\hline Valderejo & $3 / 4$ & $3 / 4$ & 1 & 1 \\
\hline Valdegovia & 5 & 5 & 5 & 5 \\
\hline Arana & $13 / 4$ & $13 / 4$ & 2 & 2 \\
\hline Marquiniz & $3 / 4$ & $3 / 4$ & 1 & 1 \\
\hline Campezo & $2 y_{2}$ & $21 / 2$ & 3 & 2 \\
\hline Quatango & 3 & 3 & 3 & 3 \\
\hline Iruña & $3 / 4$ & $3 / 4$ & 1 & 1 \\
\hline Los Guetos & $3 / 4$ & $3 / 4$ & 1 & 1 \\
\hline Villa Real & $1^{4}$ & 1 & 1 & 1 \\
\hline Ariniz & $3 / 4$ & $3 / 4$ & 1 & 1 \\
\hline Berguenda y Fontecha & $1 / 2$ & $1 / 2$ & - & 1 \\
\hline Salinillas & $1 / 2$ & $1 / 2$ & - & 1 \\
\hline Estavillo & $1 / 2$ & $1 / 2$ & - & 1 \\
\hline Mendoza & $1 / 2$ & $1 / 2$ & - & 1 \\
\hline La Braza & $1 / 4$ & $1 / 4$ & - & - \\
\hline Hijona & $1 / 4$ & $1 / 4$ & - & - \\
\hline Tuyo & $1 / 4$ & $1 / 4$ & - & - \\
\hline Portilla & $1 / 4$ & $1 / 4$ & - & - \\
\hline
\end{tabular}


la ciudad de Vitoria reclute y sufrague los dos soldados que le correspondian «con la reserva de cobrar de la hermandad" ${ }^{32}$. La diferencia entre unos datos y otros obedece, más que a las cantidades repartidas, que no varian de una leva a otra, a la obligación que cada hermandad tenía en ese año de proceder a la recluta de los soldados y de conducirlos a la ciudad de Vitoria, lo cual nos hace suponer que existian ciertas reticencias por las autoridades de las hermandades a las reclutas y al traslado de la gente de guerra ${ }^{33}$, quizás porque la mayor parte de los soldados no eran oriundos de la Provincia -el $66 \%$ en 1663 y el $79 \%$ en 1665 - y si de localidades próximas a sus lindes, según queda reflejado en el Cuadro II, donde se registran individuos nacidos en el señorío de Vizcaya, Guipúzcoa, Navarra, Burgos y La Rioja preferentemente - en total veintiocho individuos en cada una de las levas-, asi como en Galicia y en otras provincias castellanas y andaluzas, sin excluir a los naturales de los reinos de la Corona de Aragón, de los Países Bajos e incluso de Irlanda. Porque, como la Junta General de Álava establece en 1665 de forma muy precisa, los hombres reclutados por las hermandades han de ser españoles o irlandeses, "y no de otra nación, por ser gente sospecha y poco leal a la Corona de Castilla" ${ }^{34}$, a ser posible de unas mismas localidades y pertenecer a una misma familia, pues este tipo de lazos obligaba mucho más a los soldados, asumiendo así el parecer de un sector de los teóricos militares de la época que aconsejaba la formación de ejércitos nacionales, estuviesen constituidos por súbditos de un mismo reino o de varios como en el caso de la Monarquía Hispánica ${ }^{35}$. De hecho, en la leva de 1665 aparecen dos hermanos de Llodio, Francisco y Diego de Vitorica. $Y$ hermanos eran también Tomás González y Antonio González, de Logroño, aunque el primero fue reclutado en 1663 y el segundo en 1665. Por lo que se refiere al lugar de nacimiento, que no de vecindad - en casi ningún caso se indica donde residen ${ }^{36}$ - los ejemplos son más numerosos: en 1663 hay tres reclutas naturales de Narbaja (Álava), dos de Boveda y dos de Ulibarrigarboa, estos últimos seguramente emparentados ya que se apellidan Fernández de Basterra; en 1665, aparte de los hermanos de Llodio ya men-

32 A.P.A., Actas, $M 16$, fol. $135 \mathrm{v}$.

33 A.P.A, Actas, M 16, fols. 15-19v y 126v-129v. Para el sistema de reclutamiento, Contreras GaY, J., "Aportación al estudio de los sistemas de reclutamiento militar en la España Moderna", Anuario de Historia Contemporánea, Granada, 1981, págs 7-44, y RIBOT, L.A., «El reclutamiento militar en España a mediados del siglo XVII. La 'composición' de las milicias de Castilla", Cuadernos de Investigación Histórica, 9, Valladolid, 1985, págs. 63-89.

34 A.P.A, Actas, M 16, fol. 122.

35 Ver al respecto, CAMPILlo, A., La fuerza de la razón. Guerra, estado y ciencia en los tratados militares del Renacimiento, de Maquiavelo a Galileo, Murcia, 1986, págs. 61-70.

36 Las excepciones son Pedro de Arzela y Juan de Ayala, naturales y vecinos, respectivamente, de Vitoria y Ulibarri de Viña, según consta en la lista de soldados reclutados en 1663. 
cionados, nos encontramos con dos reclutas naturales de Bruselas, otros dos de Bilbao y otros tantos de Zuazo y de Subijana de Morillas (Ver Apéndices ( y II).

Cuadro 2. Procedencia geográfica de los soldados reclutados en las levas de 1663 y 1665

\begin{tabular}{|c|c|c|c|c|c|c|c|c|}
\hline Reinos o Señorios & Ciudad & $\begin{array}{r}\text { Año } \\
\text { Aldeas }\end{array}$ & $\begin{array}{l}1663 \\
\text { Sin datos }\end{array}$ & Total & Ciudad & $\begin{array}{r}\text { Año } \\
\text { Aldeas }\end{array}$ & $\begin{array}{l}1665 \\
\text { Sin datos }\end{array}$ & Total \\
\hline Provincias Vascas & 3 & 42 & - & 45 & 4 & 27 & - & 31 \\
\hline Álava & 2 & 31 & - & 33 & - & 21 & - & 21 \\
\hline Guipúzcoa & & 3 & 一 & 3 & 1 & - & - & 1 \\
\hline Vizcaya & 1 & 8 & - & 9 & 3 & 6 & - & 9 \\
\hline Navarra & 1 & 3 & - & 4 & 2 & 2 & - & 4 \\
\hline Corona de Aragón & 3 & 4 & - & 7 & 2 & 1 & 2 & 5 \\
\hline Aragón & 1 & 3 & - & 4 & - & 1 & 2 & 3 \\
\hline Cataluña & - & 1 & - & 1 & 1 & - & - & 1 \\
\hline Valencia & 1 & - & - & 1 & 1 & - & - & 1 \\
\hline Mallorca & 1 & - & - & 1 & - & - & - & - \\
\hline Corona de Castilla & 13 & 21 & - & 34 & 16 & 20 & 5 & 41 \\
\hline Asturias & 1 & 1 & - & 2 & 2 & 2 & 1 & 5 \\
\hline Galicia & 1 & 2 & - & 3 & 2 & 2 & - & 4 \\
\hline Santander & 1 & 3 & - & 4 & - & 2 & - & 4 \\
\hline La Rioja & 1 & 4 & & 5 & 2 & 4 & - & 6 \\
\hline León & - & - & - & - & - & 1 & - & 1 \\
\hline Zamora & - & - & - & - & 1 & 一 & - & 1 \\
\hline Burgos & 3 & 4 & - & 7 & 1 & 6 & 1 & 8 \\
\hline Palencia & - & - & - & - & - & - & 1 & 1 \\
\hline Valladolid & 2 & - & - & 2 & 2 & - & - & 2 \\
\hline Segovia & 1 & - & - & 1 & 1 & - & 一 & 1 \\
\hline Extremadura & - & 2 & - & 2 & - & - & 1 & 1 \\
\hline Córdoba & - & 2 & - & 2 & - & - & - & - \\
\hline Madrid & 1 & 1 & - & 2 & 1 & - & - & 1 \\
\hline Toledo & 1 & - & - & 1 & - & 2 & - & 2 \\
\hline Guadalajara & - & 1 & - & 1 & - & - & 1 & 1 \\
\hline Albacete & - & - & - & - & - & 1 & - & 1 \\
\hline Murcia & - & 1 & - & 1 & 1 & - & - & 1 \\
\hline Sevilla & - & - & - & - & 1 & - & - & 1 \\
\hline Granada & 1 & - & - & 1 & - & - & - & - \\
\hline Málaga & - & - & - & 一 & 1 & - & - & 1 \\
\hline Canarias & - & - & - & - & 1 & - & - & 1 \\
\hline Otros reinos & 1 & - & 5 & 6 & 3 & - & 6 & 9 \\
\hline Irlanda & - & - & 3 & 3 & - & - & 5 & 5 \\
\hline Países Bajos & 1 & - & 2 & 3 & 3 & - & 1 & 4 \\
\hline Sin identificar & - & - & 3 & 3 & - & - & 10 & 10 \\
\hline Total & 21 & 70 & 8 & 99 & 27 & 50 & 23 & 100 \\
\hline
\end{tabular}


La información obtenida demuestra, por otro lado, que la mayoría procedía de núcleos rurales y sólo una minoría de ciudades de mayor o menor entidad, entre las que sobresalen Vitoria, Burgos, Bilbao, San Sebastián, Logroño y Zaragoza - también los hay de Madrid, Toledo, Sevilla, Bruselas y Amberes - lo que hace pensar que su participación en la milicia estuvo condicionada más por la necesidad de subsistir que por obtener honores, como el joven cervantino que se trasladaba a Barcelona para alistarse en el ejército, aunque ambas opciones solían estar íntimamente unidas. Lo confirma, por otro lado, la presencia de determinados individuos que ya habían entrado en combate en anteriores ocasiones y para quienes la guerra era una forma de vida como cualquier otra: es el caso, por ejemplo, de Martín de Aguirre, Felipe Felipe, Martín de Ibarra, Francisco Mansoa, Pedro de Oya, Mateo de Salazar, Pablo Sancho y Diego de Soto que se alistan en 1663 y lo vuelven a hacer en 1665.

En cuanto a la edad mínima exigida para alistarse hay que decir que no podía ser inferior en ningún caso a los dieciocho años, tal como lo recoge la Junta General en 1665 y era habitual en la época - dieciséis era el límite de edad propuesto por Bernardino de Mendoza en $1595^{37}$ - Los datos del Cuadro III precisan que el grueso de los hombres reclutados en 1663 y 1665 se hallaba comprendido entre los dieciocho y los veintinueve años, aunque este porcentaje es ligeramente superior en la leva de 1665, siendo raros los reclutas que superaban los cuarenta y cinco años: cuatro individuos en 1663 y dos en 1665 -en esta fecha figuran Juan López con cuarenta y ocho años y Juan Fernández con cincuenta y dos años-. La juventud de los soldados, sin embargo, no debe hacernos pensar que estamos ante una tropa bisoña. Las señales de heridas provocadas por armas de fuego (en diferentes partes del rostro, en las manos y las piernas), según queda constancia de las características físicas anotadas por las autoridades de Álava de cada uno de los reclutas (ver Apéndice III), vienen a demostrar que al menos el 34,5 por ciento de los hombres alistados en 1663 y 1665 había participado en alguna acción militar -este porcentaje se reduce al 25 por ciento en 1663 pero se eleva al 44 por ciento en 1665-. No obstante, el problema de estas levas es que las autoridades militares ni siquiera disponían del tiempo necesario para adiestrar a la gente, aspecto que ya había sido denunciado en estos años por don Juan José de Austria ${ }^{38}$, con lo que su eficacia en el combate sería

MEndozA, B., Teórica y práctica de guerra, Madrid, 1998, edición de J.C. Saavedra Zapater y J.A. Sánchez Belén, pág. 65.

38 El informe que en 1661 envia Juan José de Austria a Felipe IV sobre la composición de la tropa no deja lugar a dudas del predominio de los bisoños en el ejército de Portugal. Ver, CASTILLA 
más que dudosa, particularmente cuando el destino de los reclutas de Álava, como ya se ha apuntado, era la Armada del Mar Océano -el tercio solicitado por el rey a Navarra en 1662 iba también destinado a esa fuerza naval, motivo por el cual se recomendaba al virrey no informar al reino sobre este punto para no alarmarlo y facilitar el servicio ${ }^{39}$ -

Cuadro 3. Edad de los reclutas

\begin{tabular}{|c|c|c|}
\hline \multirow{2}{*}{ Edad } & \multicolumn{2}{|c|}{ Reclutas } \\
\hline & 1663 & 1665 \\
\hline Menores de 20 & 5 & 12 \\
\hline Entre 20 y 24 & 33 & 27 \\
\hline Entre 25 y 29 & 24 & 31 \\
\hline Entre 30 y 34 & 14 & 15 \\
\hline Entre 35 y 39 & 10 & 5 \\
\hline Entre 40 y 44 & 9 & 8 \\
\hline Más de 44 & 4 & 2 \\
\hline
\end{tabular}

Los datos del Apéndice III, más minuciosos para 1665 que para 1663 , nos informan también sobre ciertas particularidades físicas de los reclutas. Dejando a un lado las referencias a las heridas recibidas en combate o en revertas -el número de individuos con señales de estas características es muy superior en la recluta de 1665 , donde nos encontramos a cuarenta y tres frente a sólo veintisiete en la de 1663-, y a la edad de los alistados, lo cierto es que en conjunto las personas reclutadas, salvo raras excepciones, ni estaban tullidas ni presentaban síntomas de haber padecido enfermedad alguna distinta de la viruela, y además gozaban de un aspecto físico aceptable, tanto en lo que se refiere a la estatura como a la complexión de su cuerpo, si bien tal vez hubiera varios miopes - doce en 1663 y diez en 1665-, pues según el Diccionario de Autoridades quienes tenían los ojos azulados o garzos por lo común eran cortos de vista. Por otra parte, llama la atención el hecho de que la mayoría fuera de piel clara - los que eran morenos se indicaban expresamente-, que su cabello oscilara entre el castaño claro y el castaño oscuro, aunque los había también de color negro y algunos, los menos, pelirrojos y de color rubio, y que usaran barba o bigote, cuando no eran lampiños o «barbiponientes», como así se define a quienes mostraban una barba incipiente, con la particularidad, reflejo tal vez de un cambio en la moda, de que en 1665 el grueso de los

Soto, J., Don Juan José de Austria (hijo bastardo de Felipe IV): su tabor politica y militar, Madrid, 1992, págs. 162-163.

39 Valladares, R., Felipe IV y la restauración..., pág. 150, nota 175. 
soldados parece haber adoptado el bigote y abandonado la barba, predominante en cambio entre los reclutas de 1663.

El dispositivo logístico empleado por las autoridades reales y por las de la Provincia para trasladar a los reclutas no carece de interés. En primer lugar, la Diputación General de Álava es la que designa al capitán de la tropa reclutada por concesión del monarca, ya que a este efecto se envíen de Madrid patentes en blanco de capitán, alférez y sargento, si bien se aconseja que las personas elegidos "sean de experiencia en la milicia" ${ }^{40}$. El honor de ser capitán recae en 1663 en Juan Agustín Hurtado de Mendoza y Rosales y de nuevo en 1665, aunque en esta última fecha se encontraba ausente de Vitoria sirviendo al rey en Cádiz ${ }^{41}$, estando asistido en ambas ocasiones por un paje de jineta. El alférez elegido en 1663 es Francisco de Vargas Machuca y en 1665 Domingo de Iduya, mientras que los sargentos nombrados en esos años son, respectivamente, Pedro de Arce y Marcos González. El capitán, antes de partir, debe jurar ante los diputados de la Provincia, en un acto solemne -en 1665 lo hace en su nombre el alférez que le representa-, que procurará "siempre el mayor servicio de su Majestad y crédito de la dicha compañia y cumplir con su obligación", comprometiéndose a devolver la bandera al Diputado General una vez acabada la campaña, "habiéndola defendido en conformidad de las leyes militares" ${ }^{42}$.

Organizada la compañia por el Maestre de Campo, Comisario y Diputado General de la Provincia, a quien compete esta labor -en 1663 el cargo recae en Bernardino de Isunza y Escoriaza y en 1665 en Bartolomé de Eguiluz y Barco-, sólo restaba acometer su traslado, el cual, sin duda, acarreaba graves problemas, aunque el compromiso de la Provincia consistía únicamente en conducir hasta su frontera a la gente alistada, empresa que se encarga a un comisario de las Juntas Particulares de la Provincia —en 1663 la persona nombrada es Diego de Paternina, vecino de La Guardia, y en 1665 Juan Bautista Rodríguez de Mendarrozqueta, vecino de Zárate- quien ha de entregar los soldados reclutados a las autoridades militares designadas para recibirlos, levantando acta o certificado de

\footnotetext{
A.P.A, Actas, $M 16$, fol. 115- $115 \mathrm{v}$, donde se inserta una carta del rey en este sentido de 19 de marzo de 1665 .

at A.P.A, Actas, M 16, fol. 130.

A? A.P.A, Actas, M 16, fol. 22.
} 
la entrega "al pie de la lista para resguardo de esta Provincia» ${ }^{43}$. Para que el traslado se efectúe sin problemas, la Junta Particular de Álava encarga en 1663 al Diputado General que ajuste con los comisarios de Guipúzcoa todo lo relativo a las guardas y a la conducción de la gente hasta la frontera con Guipúzcoa dado que la entrega se realiza en el campo de Arlabán, donde es recibida por el alférez José de Liaño, por nombramiento de Antonio de Landeta, veedor de la Armada de la provincia de Guipúzcoa, quien la debe trasladar luego hasta el puerto de Pasajes, lugar elegido para ser embarcada como tripulación en los galeones de la escuadra de Miguel de Oquendo, recibiendo cada soldado su paga en la cubierta de la capitana, galeón Nuestra Señora del Buen Consejo ${ }^{44}$. El procedimiento vuelve a repetirse en 1665, ahora con las autoridades del señorío de Vizcaya, pero con la particularidad de que para prevenir los obstáculos que pudiera oponer la hermandad de Llodio, dado el litigio que tiene con la Junta General, se ordena que Baltasar de Eguiluz y Barco esté asistido en todo momento por "uno de los abogados" de la Provincia ${ }^{45}$ durante el tránsito de la gente por su territorio y la entrega de la compañia en sus confines, puesto que ésta debe realizarse en Arziniega, después de atravesar la tierra de Ayala, por "distar [...] solas tres leguas la villa de Bilbao", ya que está dispuesto que los reclutas se embarquen en Portugalete para desde allí dirigirse a Colindres, donde se encuentran atracados los navíos a los que van destinados ${ }^{46}$. En este caso, todo parece indicar, sin embargo, que la ruta fue finalmente modificada, pues si bien estaba estipulado que la entrega se efectuase a Bartolomé de Azmequeta, vecino de Ampuero, por delegación de Alonso de Montoya y Múxica, veedor y contador de armadas, gente de guerra, fábricas y artillerías de las Cuatro Villas de la costa de la Mar ${ }^{47}$, lo cierto es que quien recibe la compañía es José de Solórzano, vecino de Colindres, que actuará de comisario - se le asigna un salario de setecientos maravedies diarios- por nombramiento de Luis de Necolalde, con la obligación de conducirla hasta la raya y canal de Santoña, procediendo a "alistar, socorrer, alojar y conducirs a la tropa, para lo que Luis de Necolalde, en el uso de sus competencias, conmina a

«todas y cualesquier justicias, procuradores, regidores y demás personas

43 A.P.A, Actas, M 16, fols. 22v y 130

44 A.P.A, Actas, $M 16$, fol. $22 v$. Los certificados de recepción de la gente y de abono de las pagas están fechados, respectivamente, en 13 de julio y 19 de julio de 1663.

A.P. A, Actas, M 16, fol. $126 \mathrm{v}$

A.P.A, Actas, M 16, fol. 126

A.P.A, Actas, M 16, fol. 130. 
de las villas, valles y lugares por donde pasara el dicho comisario con las dichas cien plazas de infantería le den y hagan dar todo el favor y ayuda que les pidiere, cárceles, prisiones y guardas y las demás seguridades convenientes a fin de conseguirse este servicio y que ninguno se huya ni ausente. $Y$ asimismo le darán los alojamientos ordinarios que Su Majestad manda y los bastimentos y bagajes que pidiere de unos tránsitos a otros, que pagará del dinero que para este efecto lleva, sin ocultárselos ni encarecerlos, pena de la desgracia de Su Majestad, y que serán por su cuenta los daños que se causaren. $Y$ mando a cualquiera escribano para ello requerido le asista y de los testimonios que le fueren pedidos debajo de la misma pena y de doscientos ducados para gastos de guerra" 48 .

Desde el momento en que la Provincia hace entrega de la compañia que se ha comprometido a reclutar, queda eximida de cualquier responsabilidad, lo que explica la insistencia de las autoridades de la Junta General en que se certifique dicho acto ante notario, sobre todo para evitar que se le imputen las deserciones que posteriormente se produzcan, pues éstas, a pesar de las penas establecidas en las ordenanzas militares, no eran infrecuentes. De hecho, sabemos que dos de los soldados reclutados por Álava en 1663 desertaron: Andrés de Linares, oriundo de la villa de Lille, y Gregorio Jobé, natural de Oviedo ${ }^{49}$. Quizás por este motivo, Luis de Necolalde, en 1665, advierte a los reclutas de la obligación que tienen de no contravenir las órdenes que reciban del comisario, ya que en este caso incurrirán en las penas "establecidas a los que no ejecutan las de sus superiores en el ejercicio militar, en que desde luego los doy por condenados» 50 .

Finalmente, ¿cuál fue la suerte de los soldados reclutados por la Provincia?. Las fuentes utilizadas no permiten precisar este aspecto, aunque se pueden aventurar algunas hipótesis. Cabe suponer, por un lado, que la leva de 1665 no llegó a entrar en combate, pues para cuando se embarca ya había sido derrotado en Villaviciosa el ejército del marqués de Caracena - sucede en el mes de junio de 1665- y poco tiempo después expira $\mathrm{Fe}$ lipe IV, con lo que las operaciones militares tuvieron que suspenderse previsiblemente durante el resto de la campaña de aquel año. Sí disponemos, en cambio, de referencias acerca de la suerte que corrieron en 1663 los cuatro galeones de Miguel de Oquendo, que se reúnen con la Armada del duque de Alburquerque, pero que, no pudiendo intervenir en la contienda

\footnotetext{
48 A.P.A, Actas, M 16, fol. 137. El documento de Luis de Necolalde está fechado el 18 de julio de 1665 .

49 A.P.A, Actas, M 16, fol. 29.

so A.P.A, Actas, M 16, fol. 137
} 
porque, al parecer, la tripulación enfermó y además se quedó sin vituallas, sufre un percance en el mes de octubre de 1663 en aguas de la bahía de Cádiz, adonde se trasladaba para invernar y reponerse la marinería y la infantería, chocando, por culpa de la niebla o por impericia de la marinería -el almirante había informado ese mismo año al rey acerca de la "gran falta de pilotos de las experiencias que conviene" ${ }^{51}$ para la Armada-, la capitana de Miguel de Oquendo con la almirante del duque de Alburquerque, que había estado a punto de embarrancar, con tan mala fortuna que sin los aparejos y con la proa deshecha se hizo pedazos en la playa de Rota batida por el mar, pereciendo gran parte de la tripulación ${ }^{52}$, entre los que se encontrarian algunos de los soldados reclutados por Álava, aunque por ahora no tengamos noticias ciertas de que este desastre les afectara y si indicios de que pudo ocurrir de este modo, pues resulta demasiado sospechoso que en la recluta efectuada en 1665 sólo aparezcan unos pocos soldados de la anterior, en concreto nueve individuos ${ }^{53}$.

\section{ÁPENDICE DOCUMENTAL}

1. Leva de 1663 (Por orden alfabético)

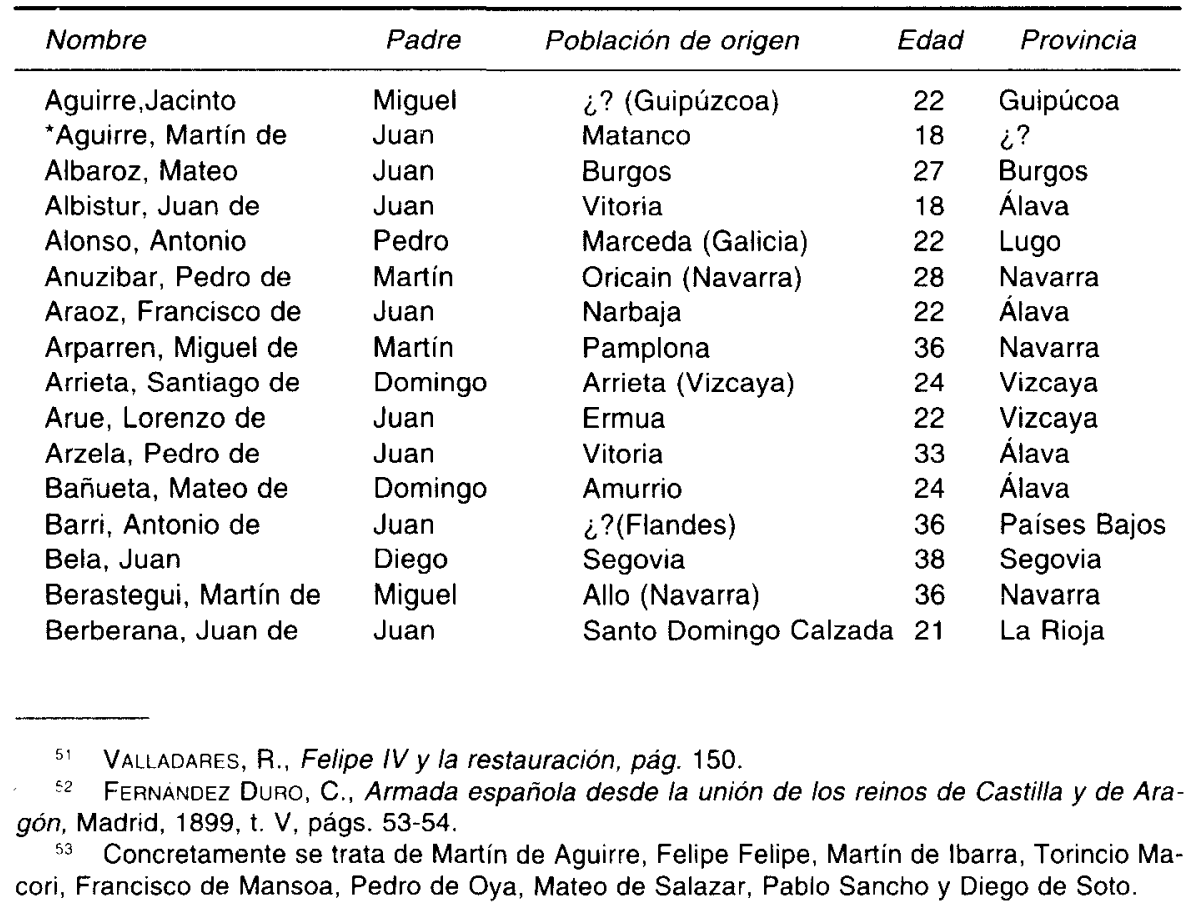


La aportación de la provincia de Álava a la contienda hispano-portuguesa...

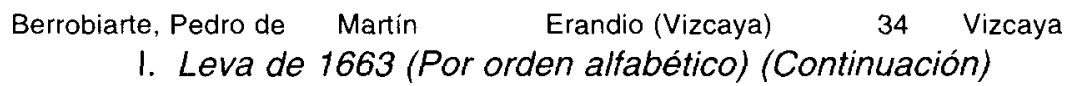

\begin{tabular}{|c|c|c|c|c|}
\hline Nombre & Padre & Población de origen & Edad & Provincia \\
\hline Bolbert, Juan & Juan & Figueras & 25 & Gerona \\
\hline Caforzada, Juan & Pedro & Zaspas (Aragón) & 25 & Zaragoza \\
\hline Cubillas, José de & Lucas & La Guardia & 22 & Álava \\
\hline Diaz, Domingo & Domingo & Castillo & 18 & Álava \\
\hline Díaz, Francisco & Francisco & Santander & 21 & Santander \\
\hline Diaz de Gobeo, J. & Juan & Aranguiz & 18 & Álava \\
\hline Echevarri, Miguel de & Miguel & Getafe & 24 & Madrid \\
\hline ^Felipe, Felipe & Pedro & Castellón de la Plana & 32 & Castellón \\
\hline Fernández, Francisco & Juan & Monterrey & 27 & Galicia \\
\hline Fernández, Juan & Juan & Toledo & 44 & Toledo \\
\hline Fernández, Lorenzo & Alonso & Mondoñedo & 22 & Lugo \\
\hline Fernández de Basterra, D. & Juan & Ulibarrigarboa & 24 & Álava \\
\hline Fernández de Bazterra, J. & Felipe & Ulibarrigarboa & 24 & Álava \\
\hline Fernández de Betonu, D. & Domingo & Ulibarrigarboa & 29 & álava \\
\hline Francisco, Pedro & Pedro & ¿? valón & 23 & Países Bajos \\
\hline Gamarra, Bautista de & Juan & Gobeo & 45 & Álava \\
\hline Garcia, Felipe & Juan & Mendijur & 26 & Álava \\
\hline García de Mendalde, M. & Juan & Ocariz & 27 & Álava \\
\hline Gómez de Baldejerala, J. & Juan & Boveda & 30 & Álava \\
\hline González, Pedro & Francisco & Elorza & 40 & Murcia \\
\hline +González, Tomás & Miguel & Logroño & 23 & La Rioja \\
\hline González de Mendivil, M. & Domingo & Arroyabe & 24 & Álava \\
\hline Guinea, Pedro de & Marcos & Miranda de Ebro & 22 & Burgos \\
\hline Herrera, Antonio & Pedro & El Carpio & 25 & Córdoba \\
\hline *Ibarra, Martín de & Domingo & Larrabetzua & 28 & Vizcaya \\
\hline Ibarra, Roque de & Pedro & ¿? (Irlanda) & 25 & Irlanda \\
\hline Iduri, Joan de & Juan & Arratia & 26 & Vizcaya \\
\hline Iloa, San Juan & San Juan & Contrasta & 32 & Álava \\
\hline Iriarte, Juan de & Pedro & Ziraidi & 28 & Navarra \\
\hline Iriarte, Pascual de & San Juan & Guetaria & 36 & Vizcaya \\
\hline Jiménez, Alonso & Alonso & Reinosa & 32 & Santander \\
\hline Jiménez, Blas & Pedro & San Mateo & 20 & Santander \\
\hline Jobe, Gregorio & Gregorio & Oviedo & 23 & Asturias \\
\hline Larrazabal, Martín de & Francisco & Lezama & 20 & Álava \\
\hline Linares, Andrés de & Rodrigo & Lille & 36 & Países Bajos \\
\hline López de Arzniega, Juan & Diego & Berguenda & 30 & Álava \\
\hline López de Heredia, Pedro & Pedro & Alegria & 23 & Álava \\
\hline Lorenzo, Marcos & Gaspar & Thelana & 40 & Extremadura \\
\hline “Macori, Thorinchi & Pheril & Castiri (Irlanda) & 34 & Irlanda \\
\hline Madrazo, Antonio Manuel & Diego & Espinosa de los Monteros & s 26 & Burgos \\
\hline *Mansoa, Francisco & Fausle (sic) & Salvatierra & 21 & Álava \\
\hline Marro, Juan & Pedro & Arranaidiaga & 42 & Vizcaya \\
\hline Martínez de Palacio, D. & Marcos & Gorgojuela & 30 & Córdoba \\
\hline Miabe, Juan Bautista de & Juan & Marquina & 40 & Vizcaya \\
\hline Munibe, San Juan de & Juan & Mendaro & 34 & Guipúzcoa \\
\hline
\end{tabular}



I. Leva de 1663 (Por orden alfabético) (Continuación)

\begin{tabular}{|c|c|c|c|c|}
\hline Nombre & Padre & Población de origen & Edad & Provincia \\
\hline Nasarrate, Juan de & Martín & Bilbao & 34 & Vizcaya \\
\hline Nieve, Pedro & Pedo & Laredo & 20 & Santander \\
\hline Ochoa de Alda, Pedro & Juan & Narbaja & 25 & Álava \\
\hline Ochoa de Arpuro, Joan & Miguel & Echevarri & 24 & Álava \\
\hline Olano, Francisco de & Tomás & Buruaga & 20 & Álava \\
\hline Ortiz, Juan & Miguel & Burgos & 29 & Burgos \\
\hline Ortiz de Foronda, Juan & Pablo & Foronda & 44 & Álava \\
\hline Ortiz de Zárate, Francisco & Juan & Domayquia & 29 & Álava \\
\hline *Oya, Pedro de & Pedro & Alcarria & 24 & Guadalajara \\
\hline Pando, Mateo de & Mateo & $¿ ?($ puerto costa) & 30 & ¿? \\
\hline Peña, Vicente de la & Antonio & Medina del Campo & 45 & Valladolid \\
\hline Pérez, Juan & Alonso & Medina de Rioseco & 40 & Valladolid \\
\hline Pérez de Tres Puentes, F. & Lucas & Trespuentes & 22 & Álava \\
\hline Quintanilla, Gregorio de & Ildefonso & Boveda & 36 & Álava \\
\hline Quiñones, Felipe de & Fernando & $¿ ?$ (Extremadura) & 20 & Extremadura \\
\hline Ribera, Juan de la & Pedro & ¿? (Valle de Mena) & 22 & Burgos \\
\hline Rodríguez, Domingo & Domingo & ¿? (Asturias) & 45 & Asturias \\
\hline Ruiz de Arriola, Juan & Antonio & Narbaja & 23 & Álava \\
\hline Ruiz de Otazu, Pedro & Andrés & Zalduendo & 30 & Burgos \\
\hline Ruiz de Otazu, Antonio & Sebastián & El Burgo & 36 & Zaragoza \\
\hline Ruiz de Velasco, Lucas & Cristóbal & Murillo de Calahorra & 28 & La Rioja \\
\hline Saenz, Pedro & Pedro & Cenicero & 27 & La Rioja \\
\hline Saenz de Buruaga, F. & Francisco & Ondategui & 34 & Álava \\
\hline ^Saiazar, Mateo de & Juan Bautista & Subijana de Morillas & 23 & Álava \\
\hline Sánchez, Juan & Juan & La Bureba & 26 & Burgos \\
\hline "Sancho, Pablo & Antonio & Pedrola & 40 & Zaragoza \\
\hline Sarria, Miguel de & Miguel & Zaragoza & 25 & Zaragoza \\
\hline Segurola, Ignacio de & Juan & Aya & 25 & Guipúzcoa \\
\hline${ }^{*}$ Soto, Diego de & Juan & Logroño & 24 & La Rioja \\
\hline Torres, Francisco de & Rafael & Mallorca & 40 & Mallorca \\
\hline Urin, Tomás de & Tomás & ¿? (Irlanda) & 35 & Irlanda \\
\hline Valle, Juan Francisco de & Juan & Madrid & 28 & Madrid \\
\hline Vargas Machuca, F. & Juan & Granada & 35 & Granada \\
\hline Villaro, Juan de & Juan & Cadaste & 20 & ¿? \\
\hline Zavalete, Manuel de & Domingo & La Guardia & 25 & Álava \\
\hline
\end{tabular}

Nota: Los asteriscos indican que también figura en la Relación de 1665. La cruz que se trata de un hermano de Antonio González que aparece en la leva de 1665. 
La aportación de la provincia de Álava a la contienda hispano-portuguesa...

II. Leva de 1665 (Por orden alfabético)

\begin{tabular}{|c|c|c|c|c|}
\hline Nombre & Padre & Población de origen & Edad & Provincia \\
\hline *Aguirre, Martin de & Juan & Matanco & 19 & ¿? \\
\hline Alonso, José & Pedro & Villalba de Losa & 22 & Burgos con Álava \\
\hline Álvarez, Domingo & Pedro & Vivero (Galicia) & 28 & Galicia \\
\hline Álvarez, Mateo & Juan & Burgos & 30 & Burgos \\
\hline Andrada, Antonio de & Antonio & Puentes de Oma & 32 & Vizcaya \\
\hline Arsua, Miguel de & Esteban & Zuaço & 23 & Álava \\
\hline Asensio de Ardemaña, J. & Juan & Mañaca (Vizcaya) & 34 & Vizcaya \\
\hline Axperren, Miguel de & Juan & Pamplona & 31 & Navarra \\
\hline Azerra, Miguel de & Miguel & Cuerva (La Sagra) & 30 & Toledo \\
\hline Biasuain, Felipe de & Garcia & Araso (Pamplona) & 28 & Navarra \\
\hline Brin, Don Diego & Don Diego & ¿? (Irlanda) & 36 & Irlanda \\
\hline Bulle, Miguel de & Esteban & ¿? (Flandes) & 20 & Países Bajos \\
\hline Calderón, Juan & Diego & Onora & 21 & ¿? \\
\hline Campo, Francisco de & $i ?$ & Cabana & 21 & Lugo \\
\hline Careaga,Juan de & Martín & Bilbao & 42 & Vizcaya \\
\hline Diaz, Bartolomé & Diego & Hechagüen & 19 & Vizcaya \\
\hline Diaz de Corquera, $\mathrm{A}$. & Agustin & Zuazo de Quartango & 22 & Álava \\
\hline Díez, Bartolomé & Martin & Tenerife & 30 & Canarias \\
\hline Díez de los Ríos, $T$. & Pantaleón & Piélago & 22 & Santander \\
\hline Echavarri, Miguel de & Juan & Mendigorria & 24 & Navarra \\
\hline Echavarría, Pedro de & Miguel & San Sebastián & 29 & Guipúzcoa \\
\hline Elguero, Simón de & Nicolás & Bilbao & 23 & Vizcaya \\
\hline${ }^{\star}$ Felipe, Felipe & Pedro & Castellón de la Plana & 34 & Castellón \\
\hline Fernández, Juan & Juan & Arenillas & 52 & Santander \\
\hline Fernández, Pedro & Francisco & Ullivarrigamboa & 23 & Álava \\
\hline Fin, Tomás de & Bemardo & Galvez & 26 & Toledo \\
\hline Garcia, Antonio & Diego & ¿? (klanda) & 28 & Irlanda \\
\hline Garcia, Antonio & Juan & Pontevedra & 18 & Pontevedra \\
\hline Garcia de Apodaca, P. & Martín & Subijana & 31 & Álava \\
\hline Garcia de Vicuña, $P$. & Pedro & Langarica & 24 & Álava \\
\hline Gastón, Carlos & Andrés & Bruselas & 27 & Países Bajos \\
\hline Gil, Anton & Juan & Clavijo & 27 & La Rioja \\
\hline Goicoechea, Juan de & Diego & Amezaga & 30 & Álava \\
\hline +González, Antonio & Miguel & Logroño & 26 & La Rioja \\
\hline González, Juan & Juan & $¿ ?$ (Asturias) & 20 & Asturias \\
\hline González, Marcos & Marcos & Pontevedra & 42 & Pontevedra \\
\hline Goroztiza, Juan de & Lorenzo & Villarreal & 28 & Álava \\
\hline Guevara, Ignacio de & Juan & Ozaeta & 19 & Álava \\
\hline Gutiérrez, Diego & Bartalomé & Entrambasaguas & 28 & Burgos \\
\hline Heredia, Pedro de & Juan & Alegría & 25 & Álava \\
\hline Herrán, Juan Bautista de & Miguel & Balpuesta & 22 & Burgos \\
\hline Ibarguen, Martín de & Martín & Bilbao & 22 & Vizcaya \\
\hline *barra, Martin de & Domingo & La Rabazua & 28 & Vizcaya \\
\hline Jacinto, Antonio & Jorge & ¿? (Galicia) & 19 & Galicia \\
\hline La Calle, Manuel de & Pedro & Samaniego & 19 & La Rioja \\
\hline La Espina, Nicolás de & Nicolás & Amberes & 22 & Países Bajos \\
\hline
\end{tabular}


II. Leva de 1665 (Por orden alfabético) (Continuación)

\begin{tabular}{|c|c|c|c|c|}
\hline Nombre & Padre & Población de origen & Edad & Provincia \\
\hline La Villanueva, Pedro de & Juan & Oviedo & 22 & Asturias \\
\hline Larrea, Pedro de & Lucas & Otazu & 28 & Vizcaya \\
\hline López, Juan & Juan & ¿?Tierra de Campo & 48 & Palencia \\
\hline López, Mateo & Hernando & Medina de Rioseco & 19 & Valladolid \\
\hline López de Iglesias, F. & Bartolomé & Quintanilleja & 29 & Burgos \\
\hline Lopez de Letona, F. & Diego & Mandiana? & 34 & ¿? \\
\hline Lloqui, Francisco & Juan & Estella & 31 & Navarra \\
\hline "Macori, Torincio & Ferriel & ¿? (Irlanda) & 36 & Irlanda \\
\hline *Mansoa, Francisco de & Fauste & Salvatierra & 24 & Álava \\
\hline Mararez de Zuaço, Miguel I & Martín & Garayo & 18 & Álava \\
\hline Mendalde, Miguel de & Juan & Ocariz & 28 & Álava \\
\hline Mesansa, Juan de & Juan & Apellaniz & 22 & Álava \\
\hline Miguel, José & José & Santa Olaya & 26 & Asturias \\
\hline Monte, Martín del & Martín & Anastio & 28 & $i ?$ \\
\hline Morales, Diego & Reymondo & ¿?(Irlanda) & 36 & Irlanda \\
\hline Nieva, Bartolomé de & Diego & Alesanco & 28 & La Rioja \\
\hline Núñez, Andrés & Pedro & Oviedo & 36 & Asturias \\
\hline Núñez, Andrés & Andrés & Sevilla & 30 & Sevilla \\
\hline *Oye, Pedro de & Pedro & ¿? La Alcarria & 26 & Guadalajara \\
\hline Ozeo, Hemando de & Hemando & Ozeo & 21 & ¿? \\
\hline Pablo, Bartolomé de & Bartolomé & Nájera & 28 & La Rioja \\
\hline Petriz, Carlos & ¿? Petriz & ¿? (Irlandés) & 44 & Irlanda \\
\hline Plaza, Juan de & Juan & $\mathrm{La} \mathrm{Hoz}$ & 40 & Albacete \\
\hline Pun, Juan de & Guillermo & Gerona & 25 & Gerona \\
\hline Quintana, Pedro de & Mateo & Arbeizia & 25 & Álava \\
\hline Quintanilla, S. de & Antonio & Valladolid & 40 & Valladolid \\
\hline Retes, Tomás de & Juan & Retes & 24 & Burgos \\
\hline Río, Francisco del & Miguel & Murcia & 36 & Murcia \\
\hline Rioseco, Juan de & Pedro & Toro & 19 & Zamora \\
\hline Rodríguez, Francisco & Francisco & ¿? (Tierra de Peñaranda) & a) 19 & Burgos \\
\hline Romero, Jorge & Bonifacio & ¿? (Aragón) & 27 & Aragón \\
\hline Romero, Juan & Juan & ¿? (Extremadura) & 40 & Extremadura \\
\hline Ruela, Juan de & Diego & Soja (Tierra de Ayala) & 26 & Álava \\
\hline Saenz, Domingo & Juan & Poza & 34 & Burgos \\
\hline Saforcada, han & Pedro & ¿? (Aragón) & 30 & Aragón \\
\hline *Salazar,Mateo de & Juan Bautista & Subijana de Morillas & 22 & Álava \\
\hline Salguero, Miguel & Diego & Málaga & 25 & Málaga \\
\hline Santa Marí a,Esteban & Juan & Madrid & 18 & Madrid \\
\hline San Miguel, Pedro de & Domingo & Orduña & 21 & Vizcaya \\
\hline San Román, Pedro de & Juan & Vicuña & 22 & Álava \\
\hline${ }^{*}$ Sancho, Pablo & Antón & Pedrola (Aragón) & 41 & Aragón \\
\hline *Soto, Diego de & Diego & Logroño & 25 & La Rioja \\
\hline Torres, Francisco de & Juan & Salsola & 32 & ¿? \\
\hline Uriarte, Santiago de & Domingo & Vaquio & 25 & Vizcaya \\
\hline Uribe, Juan de & Juan & Arregoitia & 18 & ¿? \\
\hline Uralde, Juan de & Pedro & Ozada & 26 & Álava \\
\hline
\end{tabular}


La aportación de la provincia de Álava a la contienda hispano-portuguesa...

II. Leva de 1665 (Por orden alfabético) (Continuación)

\begin{tabular}{lllll}
\hline Nombre & Padre & Población de origen & Edad & Provincia \\
\hline Valdés, Marcos de & Marcos & Canalejes & 42 & León \\
Valle, José del & Juan & Segovia & 24 & Segovia \\
Vélez del Burgo, M & Bartolomé & Gauna & 27 & Álava \\
Vitorica, Francisco & Juan & Llodio & 24 & Álava \\
Vitorica, Diego de & Juan & Llodio & 23 & Álava \\
Volven, Juan & Juan & Aujeras? & 25 & ¿? \\
Vugh, Francisco de & Juan & Bruselas & 24 & Países Bajos \\
Zuangorri, Martín de & Juan & Lagunza & 28 & ¿? \\
\hline
\end{tabular}

Nota: Los asteriscos indican que también figuran en la Relación de 1663. La cruz, que se trata de un hermano de Tomás González que aparece en la leva de 1663.

III. Datos físicos de los reclutas de 1663 y 1665

\begin{tabular}{|c|c|c|}
\hline Datos & 1663 & 1665 \\
\hline \multicolumn{3}{|l|}{ Estatura } \\
\hline Alta & - & 6 \\
\hline Buena & 3 & 43 \\
\hline Mediana & 23 & 35 \\
\hline Sin especificar & 73 & 16 \\
\hline \multicolumn{3}{|l|}{ Forma del cuerpo } \\
\hline Robusto & 1 & 7 \\
\hline Flaco & - & 7 \\
\hline Bueno & 34 & 2 \\
\hline Mediano & 12 & 2 \\
\hline Pequeño & 12 & - \\
\hline Mozo & 4 & 1 \\
\hline Sin especificar & 36 & 81 \\
\hline \multicolumn{3}{|l|}{ Piel } \\
\hline Sin vello & 4 & 6 \\
\hline Sin especificar & 95 & 94 \\
\hline \multicolumn{3}{|l|}{ Cabello } \\
\hline \multicolumn{3}{|l|}{ Color } \\
\hline Negro & 31 & 21 \\
\hline Moreno & - & 1 \\
\hline Castaño & 23 & 31 \\
\hline Castaño oscuro & 18 & 14 \\
\hline Castaño claro & 5 & 9 \\
\hline Pelirrojo & 4 & 7 \\
\hline Entrecano & 1 & 1 \\
\hline Entrecano & 6 & 1 \\
\hline Sin especificar & 11 & 15 \\
\hline \multicolumn{3}{|l|}{ Tipo de cabello } \\
\hline Calvo & 3 & 2 \\
\hline
\end{tabular}


III. Datos físicos de los reclutas de 1663 y 1665 (Continuación)

\begin{tabular}{|c|c|c|}
\hline Datos & 1663 & 1665 \\
\hline Crespo & 3 & 8 \\
\hline Sin especificar & 93 & 90 \\
\hline \multicolumn{3}{|l|}{ Barba } \\
\hline Negra & 7 & 1 \\
\hline Castaña & 6 & 11 \\
\hline Pelitroja & 27 & 4 \\
\hline Naciente & 24 & 19 \\
\hline Lampiño & 9 & 13 \\
\hline Crespa & - & 1 \\
\hline Sin especificar & 26 & 51 \\
\hline Bigote & & 26 \\
\hline Pelirrojo & 2 & 18 \\
\hline Castaño & - & 11 \\
\hline Castaño oscuro & 3 & 13 \\
\hline Sin especificar & 94 & 57 \\
\hline \multicolumn{3}{|l|}{ Rostro } \\
\hline \multicolumn{3}{|l|}{ Forma } \\
\hline Alargado & 1 & 3 \\
\hline Ancho. & 2 & 20 \\
\hline Enjuto & 3 & 1 \\
\hline Bueno & 4 & - \\
\hline Ampollar & 10 & 4 \\
\hline Sin especificar & 79 & 72 \\
\hline \multicolumn{3}{|l|}{ Color } \\
\hline Aceituno & - & 2 \\
\hline Pálido & 1 & 6 \\
\hline Moreno & 13 & 36 \\
\hline \multicolumn{3}{|l|}{ Rasgos peculiares } \\
\hline Viruela & 7 & 7 \\
\hline Pecas y manchas & 1 & 5 \\
\hline Hoyuelos & - & 2 \\
\hline Sin especificar & 77 & 42 \\
\hline \multicolumn{3}{|l|}{ Frente } \\
\hline Levantada & 1 & - \\
\hline Angosta & 1 & - \\
\hline Arrugada & - & 1 \\
\hline Sin especificar & 97 & 99 \\
\hline \multicolumn{3}{|l|}{ Nariz } \\
\hline Afilada & - & 3 \\
\hline Aguileña & 2 & - \\
\hline Curvadfa & 3 & - \\
\hline Nariguda & 1 & 4 \\
\hline Roma & 6 & 2 \\
\hline Sin especificar & 88 & 91 \\
\hline \multicolumn{3}{|l|}{ Boca } \\
\hline Desdentada & - & 1 \\
\hline
\end{tabular}


La aportación de la provincia de Álava a la contienda hispano-portuguesa...

III. Datos físicos de los reclutas de 1663 y 1665 (Continuación)

\begin{tabular}{|c|c|c|}
\hline Datos & 1663 & 1665 \\
\hline Torcida & - & 1 \\
\hline Sin especificar & 99 & 98 \\
\hline \multicolumn{3}{|l|}{ Ojos } \\
\hline \multicolumn{3}{|l|}{ Color } \\
\hline Azules & 2 & 2 \\
\hline Negros & - & 3 \\
\hline Pardos & 2 & 10 \\
\hline Garzos & 12 & 10 \\
\hline \multicolumn{3}{|l|}{ Otros rasgos } \\
\hline Bizcos & 1 & 1 \\
\hline Tuertos & 1 & 一 \\
\hline Alegres & - & 2 \\
\hline Pequeños & - & 2 \\
\hline Grandes & - & 1 \\
\hline Hundidos & 3 & 4 \\
\hline Sin especificar & 80 & 65 \\
\hline \multicolumn{3}{|l|}{ Cejas } \\
\hline Juntas & 1 & - \\
\hline Espesas & - & 3 \\
\hline Sin especificar & 98 & 97 \\
\hline \multicolumn{3}{|l|}{ Heridas } \\
\hline Mejillas & 4 & 5 \\
\hline Frente & 5 & 18 \\
\hline Nariz & 2 & 2 \\
\hline Barbilla & 3 & 1 \\
\hline Oreja & 1 & - \\
\hline Labio & 1 & - \\
\hline Ceja & 4 & 7 \\
\hline Ojos & 1 & - \\
\hline Manos y muñecas & 2 & 4 \\
\hline Pies & 1 & - \\
\hline Cabeza y cuello & 2 & 6 \\
\hline Múltiples heridas & 1 & - \\
\hline Sin especificar & 72 & 57 \\
\hline
\end{tabular}

